Invited commentary on:

\section{Functional anatomy of verbal fluency in people with schizophrenia and those at genetic risk}

\author{
The genetics of asymmetry and psychosis ${ }^{\dagger}$
}

\section{T. J. CROW}

Spence et al (2000, this issue) describe an original and incisive approach to the genetics of psychosis - an attempt to define brain connectivity in patients and family members closest to the genetic risk ('obligate carriers') by comparison with those remote from familial risk. Their findings are potentially important but I suggest an alternative interpretation: that words are simply less lateralised in those genetically predisposed to suffer from schizophrenic symptoms. This conclusion has, I believe, implications for understanding the organisation of the human brain.

The authors report three main findings: non-replication of previous reports of 'deactivation of the left superior temporal gyrus'; significant 'disconnectivity' of the left dorsolateral prefrontal cortex (DLPFC) and anterior cingulate cortex (ACC) in patients with schizophrenia and obligate carriers; and failure of deactivation of the precuneus in patients.

\section{RE-INTERPRETATION}

Each of these findings (including the failure of replication) is of interest in its own right, but all may be seen as subordinate to the fact (not remarked on) that word generation activates the prefrontal cortex on the left side, and the fourth finding (introduced into the abstract on revision) that "qualitatively aberrant ... patterns of bi-frontal activity were exhibited by patients and obligates", a finding that the authors qualify by saying that the aberrations were "statistically non-significant".

I return to the question of statistical significance later but I will first draw attention to the findings which arrested my attention as a referee.

Firstly, Fig. 1 (see page 55) shows areas of activation and deactivation that can be associated with the generation of words.

†See pp. 52-60, this issue.
In normal controls there are two obvious lateralisations - activation of the DLPFC to the left, and a deactivation in the posterior occipito-temporal cortex that encompasses the fusiform gyrus and may extend into the superior temporal gyrus (STG) lateralised to the right. Inspection of the figures relating to patients and obligate carriers reveals that, by contrast with the normal comparison group, activation is present in the DLPFC on the right (as noted in the legend) as well as on the left side, and that deactivation in the occipito-temporal region is absent posteriorly (in the area identified as the fusiform gyrus) and is bilaterally symmetrical in patients in the region of the STG, as it is also in obligate carriers. The obvious interpretation of Fig. 1 is that patients and obligate carriers are less lateralised than the normal comparison group.

Secondly, this impression is borne out by the correlational data in Fig. 3 (see page 56). Positive correlations are most extensive in controls, relative to the other groups, on the left side. In both patients and obligate carriers they are present in the DLPFC on the right side, but absent in controls. Negative correlations are conspicuous in the occipito-temporal regions on the right side in controls; they are less evident in either patients or obligate carriers.

Thirdly, and illustrating other lateralised differences in the data, patients in Fig. 2 (see page 56) differ from normals (but not from obligate carriers) in overactivation of the precuneus (as noted in the abstract) but also in a conspicuous area of activation to the right of the midline in the occipito-parietal region.

Fourthly (and also illustrating further lateralised differences), in Fig. 5 (see page 58 ), which presents the data on 'disconnectivity' from the left DLPFC and 'reciprocal disconnectivity' from the anterior cingulate cortex (ACC) in patients with schizophrenia relative to normals, the area of the ACC identified in each case is clearly to the right of the midline. Since the cingulate gyrus is not a midline structure it is presumably the right ACC that is 'functionally disconnected' from the DLPFC in patients. These findings, therefore, also appear to be susceptible to the interpretation that patients have greater bilateral representation of word generation than controls, and the second part of Fig. 5 suggests that they may be more bilaterally organised than obligate carriers.

This interpretation is confirmed by Table 4 (see page 57). If my reading of the location of the ACC in Fig. 5 is correct, all of the differences in connectivity between patients and the other two groups are lateralised, with a relative decrease in connectivity to areas including Broca's in the left frontal lobe, and an increase in connectivity to the right DLPFC. These findings are all significant at the $P<0.05$ level corrected for multiple comparisons.

\section{LATERALISATION IN THE HUMAN BRAIN}

Although the authors have de-emphasised the importance of the findings portrayed in Fig. 1 by describing the "aberrant patterns of bi-frontal activity" as "statistically non-significant", I believe that this reflects their having overlooked the fact that all their positive findings (with the possible exception of that relating to the precuneus) are lateralised, and that this oversight follows from their failure to recognise the significance of lateralisation of word generation itself. As we have known since the work of Broca (1861) and Dax (1865), some component of language is lateralised, and this may be the distinguishing feature of the human brain. The latter possibility is suggested by two recent findings. The population-based directional handedness that is present in Homo sapiens (and is a correlate of the anatomical torque of the brain (Bear et al, 1986)) is absent in chimpanzees (Marchant \& McGrew, 1996; McGrew \& Marchant, 1997), and the asymmetries of spacing of pyramidal cell columns that are present in the human (left being greater than right) are absent in the chimpanzee brain (Buxhoeveden $\&$ Casanova, 2000). Cerebral asymmetry may therefore be the characteristic that distinguishes us from our nearest surviving primate relative, and this characteristic may be crucial to our ability to 
generate words and, from words, to generate language.

\section{ASYMMETRY AND PSYCHOSIS}

The possibility that cerebral asymmetry may be related to psychosis was first considered by Crichton-Browne (1879); the possibility that it is genetically determined was first investigated in relation to handedness by Jordan (1911) and Ramaley (1913), and has been the subject of recent work and theories by Annett $(1978,1985)$ and McManus (1985). I proposed (Crow, 1984) that the genetics of psychosis and of cerebral asymmetry were related, on the basis that Brown et al (1986) had found a structural change in post-mortem brain (thinning of the parahippocampal gyrus) that was lateralised to the left. Since no aetiological factor other than a genetic one was plausible at this time, it appeared that a genetic explanation was required. The most parsimonious was that the genes for psychosis and cerebral asymmetry are the same. Subsequent anatomical studies (e.g. Crow et al, 1989a,b) strengthened the case that the structural changes are indeed related to the dimension of asymmetry (for reviews see Crow (1990, 1997a) and Petty (1999), for critiques see Weinberger et al (1991) and Bartley et al (1993), and for counter-critiques see Crow et al (1995)).

Given this background (and their interest in word generation and the genetics of schizophrenia), one can ask whether Spence et al (2000, this issue) might not have considered that the genetics of asymmetry and psychosis are linked as a prior hypothesis. Had they done so the range of predictions would have been reduced and the correction for number of comparisons curtailed. The statistical significance of the finding of bilateral activation of the DLPFC in patients and obligate carriers would appear quite different from that presented in the abstract. Spence et al may point to ignorance of this literature as their defence. However, two of Spence's co-authors are also co-authors of a paper of similar experimental design (Sharma et al, 2000) which examines exactly this hypothesis in relation to anatomical asymmetries. The frontooccipital torque, assessed as brain widths, was reduced in patients and in obligate carriers. Moreover, a further study with common authorship (Orr et al, 1999) reports that mixed handedness, another index of reduced asymmetry, is increased in patients and first-degree relatives compared with the general population.

\section{THE WIDER CONTEXT}

The central issue is the genetic determination of asymmetry. Following Crow (1984, 1990, 1993), Annett (1997, 1999), Klar (1999) and Yeo et al (1999) have each discussed a genetic relationship between asymmetry and psychosis, but no gene for either has yet been located (see DeLisi \& Crow (1999) for progress in genome scans in psychosis and Crow (1999) for theories of asymmetry). The question can be placed in a wider context. Annett's (1985) hypothesis that variation in degrees of handedness is associated with variation in academic ability is supported, in a modified form, by observations on the National Child Development Study (Crow et al, 1998). In 12000 11-year-olds, academic ability was predicted by degrees of handedness in a square-checking task. Those at the extremes were disadvantaged relative to those less strongly lateralised (as predicted by Annett, 1985) but those who were most delayed in verbal ability were those who were closest to having equal hand skill (i.e. ambidexterity). These findings are consistent with the theories of Orton (1937) and Zangwill (1960) that failure to lateralise or delay in lateralisation is a major determinant of reading skill and academic ability; they are also relevant to psychosis, as children who later develop a schizophrenic illness have been shown to be slow in learning to read (Crow et al, 1995) and closer to the point of equal hand skill at the ages of seven and eleven years (Crow et $a l, 1996)$. Genetic variation related to psychosis is thus also related to the development of verbal ability and reading skill.

Revision of the concept of 'general intelligence' is required. It is not that there are a number of components of some mysterious overall cerebral capacity, but rather that variation in the genetic mechanism that enabled the evolution of the (speciesdefining) capacity for language is associated with variation in its component functions, including particularly the ability to attach words to categories. This ability is lateralised and there are degrees of lateralisation. Once the significance of lateralisation is grasped the concept of general intelligence can be discarded and the phenomena of psychosis as manifestations of a failure of lateralisation acquire new significance.
Huxley et al (1964) were the first to ask what advantage balances the disadvantage associated with the genetic predisposition to psychosis. The answer that I have given is that schizophrenia is the price that Homo sapiens pays for language (Crow, 1996, 1997b). A corollary of this claim is that the symptoms of schizophrenia can be considered as deviations in the neural basis of language, as "language at the end of its tether" (Crow, 1998c). Seen from this viewpoint, Spence et al's failure to take into account the dimension of lateralisation overlooks the critical feature of the human brain (the principle around which its connectivity must be organised) and subjugates the principal clues that we have regarding the neural basis of language (the nuclear symptoms of schizophrenia) to the questionable categorical concept of a disease entity - the DSM-IV diagnosis of schizophrenia (American Psychiatric Association, 1994).

\section{COMPETING HYPOTHESES}

One can ask whether there is any other hypothesis which can account for the findings and relate them to the genetics of psychosis. Spence $e t$ al's own hypotheses were simply that there was a failure of left superior temporal gyrus 'deactivation' (this hypothesis was falsified by their findings) and that 'fronto-temporal disconnectivity' provides a trait marker for schizophrenia. But what genes would one expect to govern frontotemporal (or fronto-frontal) connections and at what stage in evolution might variation relating to these genes have arisen? A merit of the asymmetry/cerebral dominance theory is that it specifies a change (deviation across the fronto-occipital axis) that is simple, that according to the evidence cited above occurred recently in the hominid lineage, and that can be related, at least in principle, to the functional capacity that has to be explained, namely language. The theory can also be related to the evidence for deviations in anatomical asymmetry (Crow, 1990, 1997a; Highley et al, 1998, 1999; McDonald et al, 2000) as well as to the time course of development of components of language (Crow et al, 1998; Crow, $1998 a, b)$. It specifies a single change that relates to occipito-parieto-temporal heteromodal association cortex as well as to the fronto-occipital torque which is diminished in those who develop schizophrenic symptoms (Bilder et al, 1994). For this reason I 
suggest that reappraisal of the important findings of Spence et al is necessary for progress in the genetics of psychosis to be made.

\section{REFERENCES}

American Psychiatric Association (1994) Diagnostic and Statistical Manual of Mental Disorders (4th edn) (DSM-IV). Washington, DC: APA.

Annett, M. (1978) A Single Gene Explanation of Right and Left Handedness and Brainedness. Coventry: Lanchester Polytechnic.

- (1985) Left, Right, Hand and Brain: The Right Shift Theory. London: Lawrence Erlbaum.

- (1997) Schizophrenia and autism considered as products of an agnosic right shift gene. Cognitive Neuropsychiatry, 2, 195-240.

- (1999) The theory of an agnosic right shift gene in schizophrenia and autism. Schizophrenia Research, 39 177-182

Bartley, A. J., Jones, D. W., Torrey, E. F., et al (1993) Sylvian fissure asymmetries in monozygotic twins: a test of laterality in schizophrenia. Biological Psychiatry, 34, 853-863.

Bear, D. M., Schiff, D., Saver, J., et al (1986)

Quantitative analysis of cerebral asymmetry; frontooccipital correlation, sexual dimorphism and association with handedness. Archives of Neurology, 43, 598-603.

Bilder, R. M., Wu, H., Degreef, G., et al (1994)

Yakovlevian torque is absent in first episode schizophrenia. American Journal of Psychiatry, I5I, 14371447.

Broca, P. (186I) Remarques sur la siegé de la faculté du langue. Bulletin de la Société Anatomique de Paris (2nd series), 6, 330-357.

Brown, R., Colter, N., Corsellis, J. A. N., et al (1986) Postmortem evidence of structural brain changes in schizophrenia. Differences in brain weight, temporal horn area, and parahippocampal gyrus compared with affective disorder. Archives of General Psychiatry, 43. $36-42$.

\section{Buxhoeveden, D. \& Casanova, M. (2000)}

Comparative lateralization patterns in the language area of normal human, chimpanzee, and rhesus monkey brain. Laterality, in press.

Crichton-Browne, J. (1879) On the weight of the brain and its component parts in the insane. Brain, 2, 42-67.

Crow, T. J. (1984) A re-evaluation of the vira hypothesis: is psychosis the result of retroviral integration at a site close to the cerebral dominance gene? British Journal of Psychiatry, 145, 243-253.

- (1990) Temporal lobe asymmetries as the key to the etiology of schizophrenia. Schizophrenia Bulletin, 16 433-443.

- (1993) Sexual selection, Machiavellian intelligence and the origins of psychosis. Lancet, 342, 594-598.

- (1995) The relationship between morphologic and genetic findings in schizophrenia: an evolutionary perspective. In Schizophrenia: An Integrated View. Alfred Benzon Symposium 38 (eds R. Fog \& J. Gerlach), pp. 15-25. Copenhagen: Munksgaard.

TIM J. CROW, FRCPsych, Prince of Wales International Centre, University Department of Psychiatry, Warneford Hospital, Oxford OX3 7JX. e-mail: tim.crow@psychiatry.ox.ac.uk

(First received 7 September 1999, accepted 8 September 1999)

- (1996) Language and psychosis: common evolutionary origins. Endeavour, 20, 105-109.

- (1997a) Schizophrenia as failure of hemispheric dominance for language. Trends in Neurosciences, 20 339-343.

_ (1997b) Is schizophrenia the price that Homo sapien pays for language? Schizophrenia Research, 28, 127-141.

_ (1998a) Sexual selection, timing and the descent of Man: a genetic theory of the evolution of language. Current Psychology of Cognition, 17, 1079-1114.

- (1998b) Why cerebral asymmetry is the key to the origin of Homo sapiens: how to find the gene or eliminate the theory. Current Psychology of Cognition, I7, 1237-1277.

- (1998c) Nuclear schizophrenic symptoms as a window on the relationship between thought and speech. British Journal of Psychiatry, 173, 303-309.

_ (1999) Cerebral asymmetry, language and psychosis - the case for a Homo sapiens-specific sexlinked gene for brain growth (commentary). Schizophrenia Research, 39, 219-231.

_ , Ball, J., Bloom, S. R., et al (1989a) Schizophrenia as an anomaly of development of cerebral asymmetry. A postmortem study and a proposal concerning the genetic basis of the disease. Archives of General Psychiatry, 46, II45-II50.

\section{_, Colter, N., Frith, C. D., et al (1989b)}

Developmental arrest of cerebral asymmetries in early onset schizophrenia. Psychiatry Research, 29, 247253.

_, Done, D. J. \& Sacker, A. (1995) Childhood precursors of psychosis as clues to its evolutionary origins. European Archives of Psychiatry and Clinical Neuroscience, 245, 6I-69.

_, _ \& _ (1996) Cerebral lateralization is delayed in children who later develop schizophrenia. Schizophrenia Research, 22, $18 \mid-185$.

_ , Crow, L. R., Done, J., et al (1998) Relative hand skill predicts academic ability: global deficits at the point of hemispheric indecision. Neuropsychologia, 36, 1275 1282

Dax, M. (1865) Lésions de la moitié gauche de l'éncephale coincident avec l'oubli des signes de la pensée. Gazette Hebdomadal de Médecin et Chirurgie, II, 259-260.

DeLisi, L. E. \& Crow, T. J. (1999) Chromosome Workshops 1998: current state of psychiatric linkage. American Journal of Medical Genetics, 88, 215-218.

Highley, J. R., Esiri, M. M., Cortina-Borja, M., et al (1998) Anomalies of cerebral asymmetry in schizophrenia interact with gender and age of onset: a post mortem study. Schizophrenia Research, 34, 13-25.

\section{_ , McDonald, B., Walker, M. A., et al (1999)}

Schizophrenia and temporal lobe asymmetry: a postmortem stereological study of tissue volume. British journal of Psychiatry, 175, 127-134.
Huxley, J., Mayr, E., Osmond, H., et al (1964) Schizophrenia as a genetic morphism. Nature, 204 220-221.

Jordan, H. E. (19II) The inheritance of left-handedness. American Breeders' Magazine, 2, 19-29.

Klar, A. J. S. (1999) Genetic models for handedness, brain lateralization, schizophrenia and manicdepression. Schizophrenia Research, 39, 207-218.

Marchant, L. F. \& McGrew, W. C. (1996) Laterality of limb function in wild chimpanzees of Gombe National Park: comprehensive study of spontaneous activities. Journal of Human Evolution, 30, 427-443.

McDonald, B., Highley, J. R, Walker, M. A., et al (2000) Anomalous asymmetry of fusiform and parahippocampal gyrus grey matter in schizophrenia: a post-mortem study. American Journal of Psychiatry, in press.

McGrew, W. C. \& Marchant, L. F. (1997) On the other hand: current issues in and meta-analysis of the behavioral laterality of hand function in nonhuman primates. Yearbook on Physical Anthropology, 40, 20I232

McManus, I. C. (1985) Handedness, language dominance and aphasia: a genetic model. Psychological Medicine, Monograph Supplement, no. 8, 1-40.

Orr, K., Cannon, M., Gilvarry, C. M., et al (1999) Schizophrenic patients and their first degree relatives show an excess of mixed handedness. Schizophrenia Research, 39, 167-176.

Orton, S.T. (1937) Reading, Writing and Speech Problems in Children. New York: Norton

Petty, R. G. (1999) Structural asymmetries of the human brain and their disturbance in schizophrenia. Schizophrenia Bulletin, 25, I2I-139.

Ramaley, F. (1913) Inheritance of left-handedness. American Naturalist, 47, 730-738.

Sharma, T. M., Lancaster, E., Simindsson, T., et al (2000) Lack of cerebral asymmetry in familial schizophrenic patients and their relatives: confirmation of Crow's hypothesis. Schizophrenia Research, in press.

Spence, S. A., Liddle, P. F., Stefan, M. D., et al (2000) Functional anatomy of verbal fluency in people with schizophrenia and those at genetic risk: focal dysfunction and distributed disconnectivity reappraised. British Journal of Psychiatry, 176, 52-60.

Weinberger, D. R., Suddath, R. C., Casanova, M. F., et al (1991) Crow's 'Lateralisation hypothesis for schizophrenia'. Archives of General Psychiatry, 48, 85 .

Yeo, R. A., Gangestad, S. W., Edgar, C., et al (1999) The evolutionary-genetic underpinnings of schizophrenia: the developmental instability model. Schizophrenia Research, 39, 197-206.

Zangwill, O. L. (1960) Cerebral Dominance and its Relation to Psychological Function. Edinburgh: Oliver \& Boyd. 